\title{
DYNAMICAL NMR STUDIES ON THALLIUM(II) MESO-TETRAPHENYLPORPHYRIN ACETATE
}

\author{
JYH-CHING CHEN, HUEY-SHWU JANG and JYH-HORUNG CHEN*
}

Department of Chemistry, National Chunghsing University, Taichung, Taiwan 40227, R.O.C.

and

\section{LIAN-PIN HWANG}

Department of Chemistry, National Taiwan University and Institute of Atom and Molecular Science, Academia Sinica, Taipei, Taiwan, R.O.C.

(Received 18 March 1991; accepted 20 May 1991)

\begin{abstract}
It is shown from the proton resonances spectra of thallium(III) meso-tetraphenylporphyrin acetate that the intermolecular exchange of the acetato group has an activation energy of $4.1 \mathrm{kcal} \mathrm{mol}^{-1}$ in $\mathrm{CD}_{2} \mathrm{Cl}_{2}$. In the slow exchange region, the methyl and carbonyl carbons of the acetato group are observed at $18.8 \mathrm{ppm}$ [with ${ }^{3} \mathrm{~J}\left(\mathrm{Tl}-{ }^{13} \mathrm{C}\right)$ coupling constant $280 \mathrm{~Hz}$ ] and $174.9 \mathrm{ppm}$ [with ${ }^{2} \mathrm{~J}\left(\mathrm{Tl}-{ }^{13} \mathrm{C}\right)$ coupling constant $235 \mathrm{~Hz}$ ], respectively, at $-90^{\circ} \mathrm{C}$. The phenomenon of the rotation of phenyl groups in the complex from the angle $90-60^{\circ}$ relative to the $\mathrm{N}_{4}$ plane to approximately $0^{\circ}$ was identified and examined by using ${ }^{13} \mathrm{C}$ and ${ }^{1} \mathrm{H}$ NMR spectroscopy at various temperatures.
\end{abstract}

Thallium(III) meso-tetraphenylporphyrin acetate, $\mathrm{Tl}(\mathrm{tpp})(\mathrm{OAc})$, (shown in Fig. 1) is a compound suitable for dynamical NMR studies. It is believed that $\mathrm{Tl}(\mathrm{tpp})(\mathrm{OAc})$ has a coordination number of five, rather than six, because the thallium atom is displaced out of the porphyrin plane by about $0.9 \AA .^{1-4}$

In an NMR study of Tl(tpp)(OAc), Abraham et $a .^{5-7}$ have reported that the methyl protons of the apical acetate ligand were observed as a sharp singlet at $\delta=-0.03 \mathrm{ppm}$, with no evidence of coupling of the thallium nuclei with the acetate group. Neither the carbonyl nor methyl signals of the acetate ligand in the ${ }^{13} \mathrm{C}$ NMR spectra was found. However, all other ${ }^{13} \mathrm{C}$ signals in the porphyrin were clearly observed. Hence, they surmised that this effect might be due to the broadening of the ${ }^{13} \mathrm{C}$ signal through an exchange process involving the apical ligand. In the present communication, the proton and ${ }^{13} \mathrm{C}$ NMR spectra of $\mathrm{Tl}(\mathrm{tpp})(\mathrm{OAc})$ in solution at low temperatures are examined to confirm the previous inference and to determine the value of the

* Author to whom correspondence should be addressed.

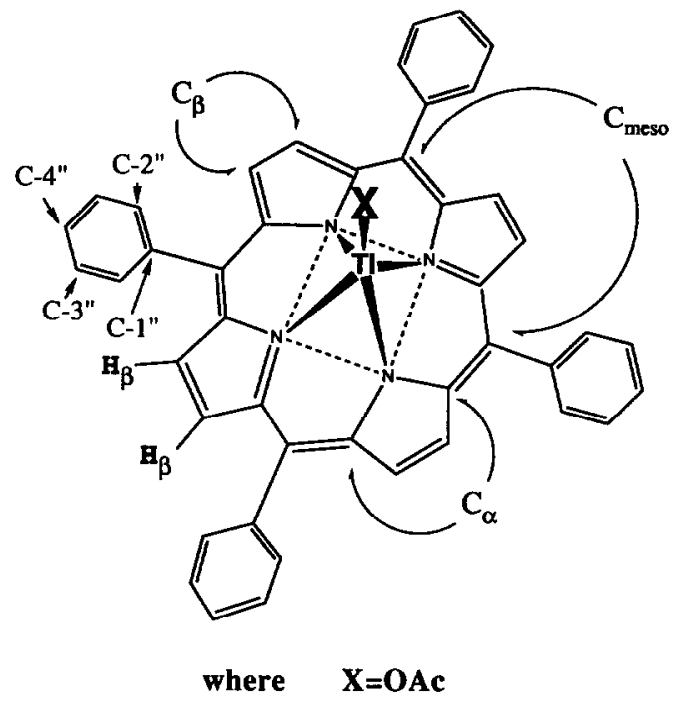

Fig. 1. Structure of the Tl(tpp)(OAc) complex.

activation energy for the exchange process. Furthermore, an abnormal conformation change at low temperatures has been detected.

On cooling a $0.05 \mathrm{M}$ solution of $\mathrm{Tl}(\mathrm{tpp})(\mathrm{OAc})$ in $\mathrm{CD}_{2} \mathrm{Cl}_{2}$ (Fig. 2), the methyl proton signal, which 


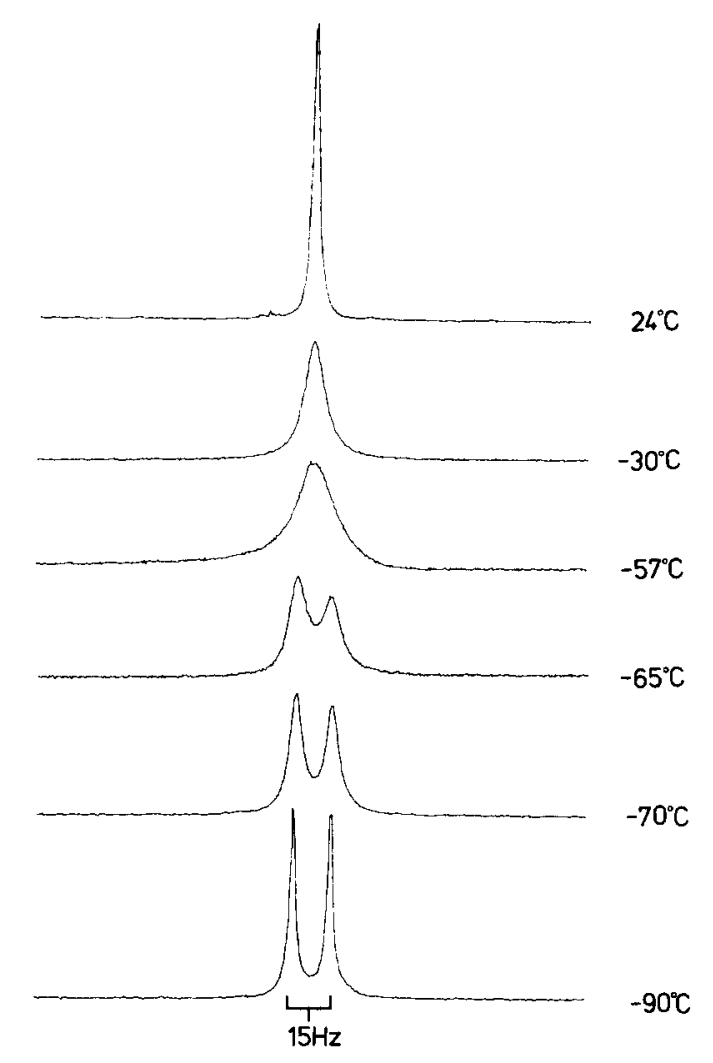

Fig. 2. $300 \mathrm{MHz}{ }^{1} \mathrm{H}$ NMR spectra of the axial acetato protons in $\mathrm{Tl}(\mathrm{tpp})(\mathrm{OAc})$ in $\mathrm{CD}_{2} \mathrm{Cl}_{2}$ at various temperatures.

displays a single peak at room temperature $(\delta=$ $0.06 \mathrm{ppm}$ ), broadens (temperature of coalescence, $T_{\mathrm{c}}-57^{\circ} \mathrm{C}$ ) and finally splits into two peaks with a separation of $14.7 \mathrm{~Hz}$. The process is completely reversible, and the results measured at $300 \mathrm{MHz}$ confirm the separation as a coupling ${ }^{4} J(\mathrm{Tl}-\mathrm{H})$ rather than a chemical-shift difference. The rate process is treated as a simple two-site exchange rate process and the use of the usual coalescence analysis yields the exchange rate of $32.65 \mathrm{~s}^{-1}$ at $-57^{\circ} \mathrm{C}$, which corresponds to an activation energy $\left(E_{\mathrm{a}}\right)$ of $4.1 \mathrm{kcal} \mathrm{mol}^{-1}$.

${ }^{13} \mathrm{C}$ NMR data for $\mathrm{Tl}(\mathrm{tpp})(\mathrm{OAc})$ at different temperatures is shown in Table 1 . At $-90^{\circ} \mathrm{C}$ (or $-75^{\circ} \mathrm{C}$ ), because the intermolecular exchange is extremely slow, methyl and carbonyl carbons of the acetato group are observed at $18.8 \mathrm{ppm}$ [with ${ }^{3} \mathrm{~J}\left(\mathrm{Tl}-{ }^{13} \mathrm{C}\right)$ coupling constant $\left.280 \mathrm{~Hz}\right]$ and 174.9 ppm [with ${ }^{2} J\left(\mathrm{Tl}-{ }^{13} \mathrm{C}\right)$ coupling constant $235 \mathrm{~Hz}$ ], respectively. At $24^{\circ} \mathrm{C}$, the rate of intermolecular exchange of the acetato ligand is $352 \mathrm{~Hz}$. The exchange rate is comparable with the coupling frequency of $\mathrm{Tl}-{ }^{13} \mathrm{C}$, i.e. $258 \pm 23 \mathrm{~Hz}$. In this intermediate exchange region, the signals are broadened beyond detection. Hence, no signal of the axial ${ }^{13} \mathrm{C}$ has been found at $24^{\circ} \mathrm{C}$.
The abnormal conformation change due to the rotation of the phenyl group in the complex is also observed from the ${ }^{13} \mathrm{C}$ and ${ }^{1} \mathrm{H}$ NMR spectra at different temperatures. The temperature variation of the c-2" carbon spectrum of Tl(tpp)(OAc) is shown in Fig. 3 as from a doublet of doublets at $24^{\circ} \mathrm{C}$ to a triplet at $-90^{\circ} \mathrm{C}$. This indicates that the dihedral angles between the mean plane of the porphyrin skeleton and the planes of the four phenyl groups vary from a range of $90-60^{\circ} 3,8$ to about $0^{\circ}$. Consequently, the two ortho carbons in the same phenyl group become more equivalent and the inner peaks of doublet of doublets merge together with decreasing temperature. Also, the steric hindrance between the phenyl groups and $\beta$-pyrrole increases. It causes the $\beta$-pyrrole proton to shift downfield by about $39 \mathrm{~Hz}$ from $9.07 \mathrm{ppm}$ at $24^{\circ} \mathrm{C}$ to $9.20 \mathrm{ppm}$ at $-90^{\circ} \mathrm{C}$. All other phenyl protons are shifted downfield about $16 \pm 5 \mathrm{~Hz}$ (shown in Table 2). Furthermore, the chemical shift of $\mathrm{C}_{\alpha}$ (and $c$-1") shifts upfield about $53 \mathrm{~Hz}$ from 150.5 (or 142.4) ppm to 149.8 (or 141.7) ppm (shown in Table 1). Those effects are also evidenced from 2D NOESY at $-90^{\circ} \mathrm{C}$ and $24^{\circ} \mathrm{C}$ as shown in Figs $4(\mathrm{a})$ and (b), respectively. Figure 4(a) indicates that there is a strong through space steric interaction between the protons of $\beta$-pyrrole and the phenyl protons, while in Fig. 4(b), there is only a weak through space interaction between the protons of $\beta$-pyrrole and ortho phenyl protons but no signal indicates the interaction between the protons of $\beta$-pyrrole and other phenyl protons. All these observations show that, as the temperature decreases, the phenyl groups rotate from the planes at the angle of $90-60^{\circ}$
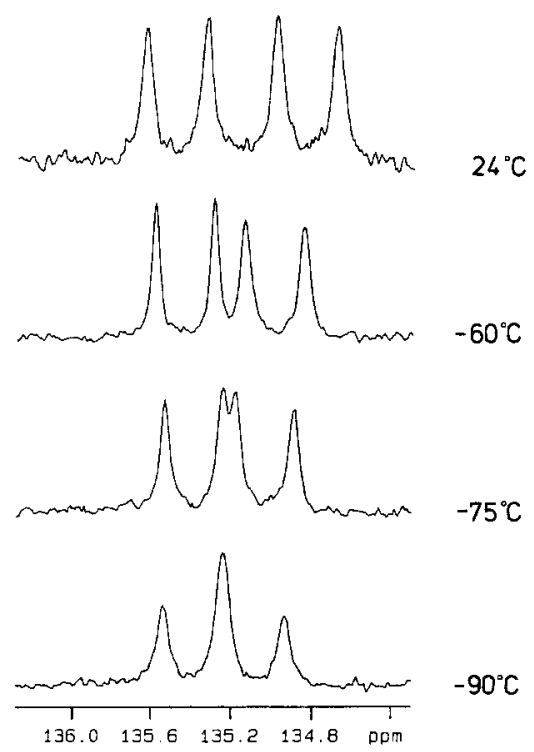

Fig. 3. Temperature dependence of chemical shifts for the $\mathrm{C}-2^{\prime \prime}$ carbons of $\mathrm{Tl}(\mathrm{tpp})(\mathrm{OAc})$ in $\mathrm{CD}_{2} \mathrm{Cl}_{2}$. 
Table $1 .{ }^{13} \mathrm{C}$ chemical shifts $(\delta)$ and thallium-carbon coupling constant $(J)$ in Hertz of Tl(tpp) $(\mathrm{OAc})$ in $\mathrm{CD}_{2} \mathrm{Cl}_{2}{ }^{a}$

\begin{tabular}{|c|c|c|c|c|c|c|c|c|c|}
\hline Temperature $\left({ }^{\circ} \mathrm{C}\right)$ & $\mathrm{C}_{\alpha}$ & $\mathrm{C}_{\beta}$ & $\mathrm{C}_{\text {meso }}$ & C-1" & C-2" & C-3" & C-4" & $\mathrm{COC}^{*} \mathrm{H}_{3}$ & $\mathrm{C}^{*} \mathrm{OCH}_{3}$ \\
\hline Room temperature ${ }^{b}$ & $\begin{array}{c}149.3 \\
(17)\end{array}$ & $\begin{array}{l}131.8 \\
(120)\end{array}$ & $\begin{array}{l}121.6 \\
(147)\end{array}$ & $\begin{array}{c}141.1 \\
(27)\end{array}$ & $\begin{array}{c}133.8 \\
(22) \\
134.6 \\
(18)\end{array}$ & 126.1 & 127.3 & - & - \\
\hline 24 & $\begin{array}{c}150.5 \\
(18)\end{array}$ & $\begin{array}{l}132.9 \\
(118)\end{array}$ & $\begin{array}{l}122.7 \\
(148)\end{array}$ & $\begin{array}{c}142.4 \\
(27)\end{array}$ & $\begin{array}{c}134.8 \\
(25) \\
135.5 \\
(23)\end{array}$ & 127.2 & 128.4 & - & - \\
\hline-60 & $\begin{array}{c}150.1 \\
(18)\end{array}$ & $\begin{array}{l}133.1 \\
(118)\end{array}$ & $\begin{array}{l}122.7 \\
(148)\end{array}$ & $\begin{array}{c}142.0 \\
(28)\end{array}$ & $\begin{array}{c}135.0 \\
(22) \\
135.4 \\
(22)\end{array}$ & 127.4 & 128.4 & - & 一 \\
\hline-75 & $\begin{array}{c}149.9 \\
(17)\end{array}$ & $\begin{array}{l}133.1 \\
(118)\end{array}$ & $\begin{array}{l}122.5 \\
(148)\end{array}$ & $\begin{array}{c}141.8 \\
(28)\end{array}$ & $\begin{array}{c}135.0 \\
(22) \\
135.4 \\
(22)\end{array}$ & 127.3 & 128.3 & $\begin{array}{c}18.8 \\
(279)\end{array}$ & $\begin{array}{l}174.8 \\
(234)\end{array}$ \\
\hline-90 & $\begin{array}{c}149.8 \\
(17)\end{array}$ & $\begin{array}{l}133.1 \\
(118)\end{array}$ & $\begin{array}{l}122.5 \\
(148)\end{array}$ & $\begin{array}{c}141.7 \\
(28)\end{array}$ & $\begin{array}{c}135.1 \\
(23) \\
135.4 \\
(23)\end{array}$ & 127.3 & 128.3 & $\begin{array}{c}18.8 \\
(280)\end{array}$ & $\begin{array}{l}174.9 \\
(235)\end{array}$ \\
\hline
\end{tabular}

${ }^{a}$ Chemical shifts in ppm relative to TMS. Values in parentheses beneath are $J\left(\mathrm{Tl}-{ }^{13} \mathrm{C}\right)$ coupling constants in Hertz.

${ }^{b}$ From ref. 6.

relative to the $\mathrm{N}_{4}$ plane to the planes approximately parallel to it.

\section{EXPERIMENTAL}

\section{Dynamic NMR spectroscopy}

Proton and ${ }^{13} \mathrm{C}$ NMR spectra were recorded on a Varian VXR-300 spectrometer in dichloromethane$d_{2}$, locked on solvent deuterium, and referenced to the residual solvent peak. The temperature of the spectrometer probe was calibrated by the shift difference of methanol resonance in the ${ }^{1} \mathrm{H}$ NMR spectrum.

\section{Preparation of $\mathrm{T} 1(\mathrm{tpp})(\mathrm{OAc})$}

Tl(tpp)(OAc) was prepared as described elsewhere. ${ }^{5,9}$ It was dissolved in $\mathrm{CD}_{2} \mathrm{Cl}_{2}$ to give a concentration of $0.05 \mathrm{M}$ for the NMR measurement.

Table 2. Proton chemical shifts $(\delta)$ and thallium-proton coupling constant $J$ in Hertz for the Tl(tpp)(OAc) complex in $\mathrm{CD}_{2} \mathrm{Cl}_{2}$ in the absence of the axial ligand ${ }^{a}$

\begin{tabular}{lccc}
\hline Temperature $\left({ }^{\circ} \mathrm{C}\right)$ & $\mathrm{H}_{\beta}(\beta$-pyrrole $)$ & $o$-phenyl & $m, p$-phenyl \\
\hline Room temperature $^{b}$ & 9.02 & $8.31,8.08$ & 7.73 \\
& $(64 \mathrm{~Hz})$ & & \\
24 & 9.07 & $8.35,8.18$ & 7.82 \\
& $(63 \mathrm{~Hz})$ & & \\
-90 & 9.20 & $8.38,8.25$ & 7.88 \\
& $(64 \mathrm{~Hz})$ & & \\
\hline
\end{tabular}

\footnotetext{
${ }^{a}$ Chemical shifts in ppm relative to TMS. Values in parentheses beneath are $J(\mathrm{Tl}-\mathrm{H})$ coupling constants in Hertz.

${ }^{b}$ From ref. 5.
} 


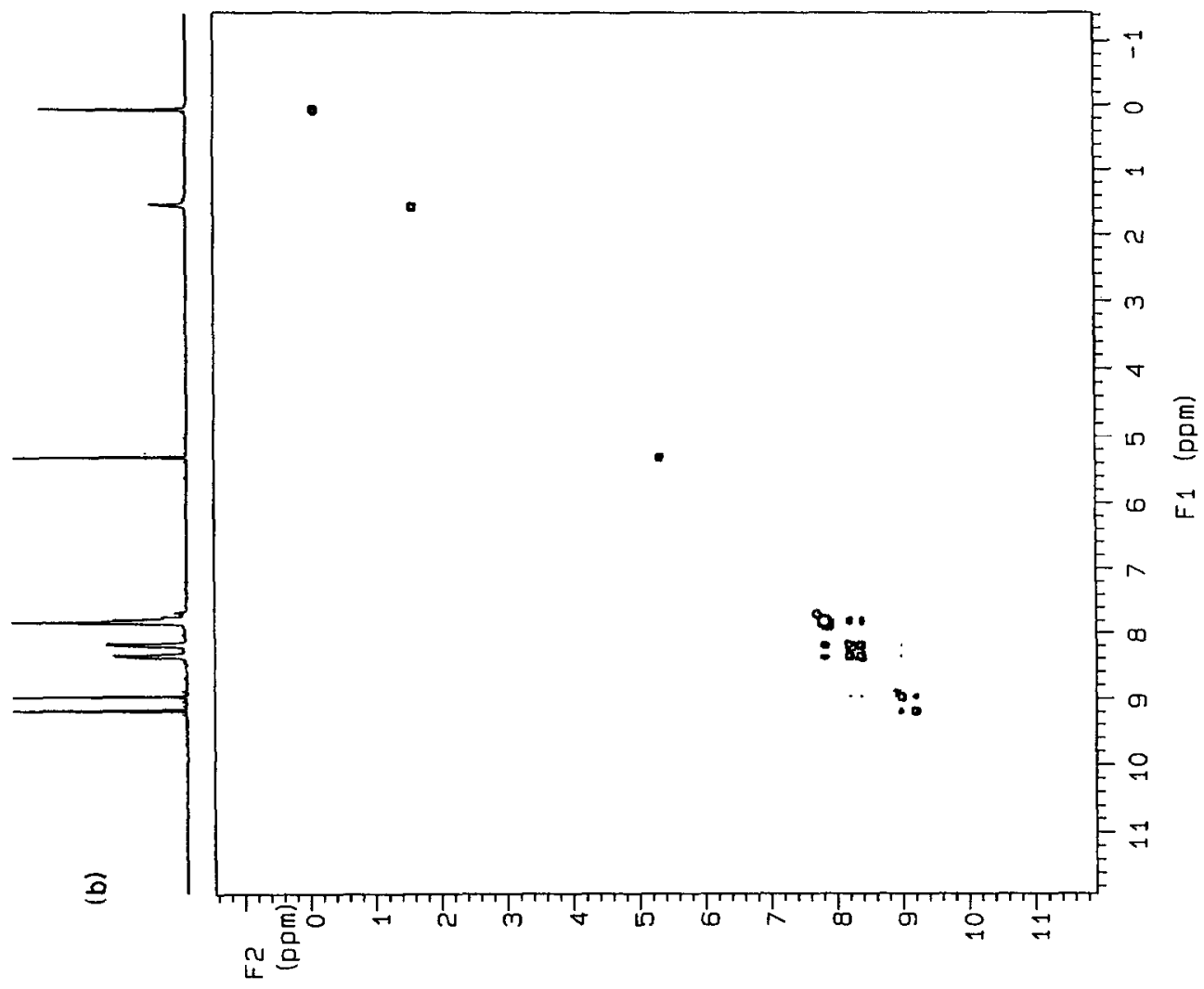

는 으

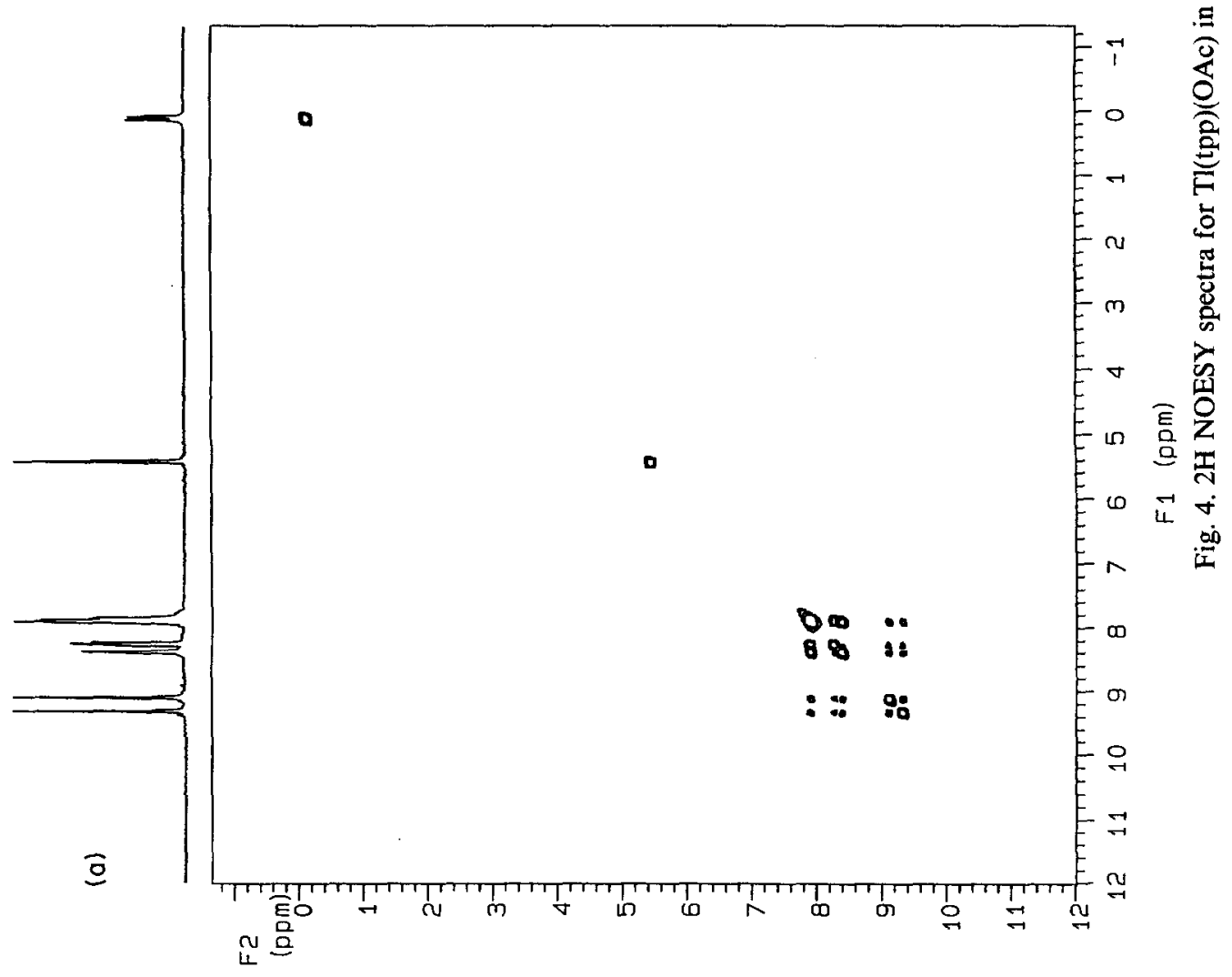


Acknowledgments-Financial support of the National Research Councils of the R.O.C. under Grant NSC 800208-M005-13 is gratefully acknowledged. The authors wish to thank Dr T. Y. Chau for the help in preparing the Tl(tpp)(OAc). Special thanks to Dr Fung E. Hong for illuminating discussions.

\section{REFERENCES}

1. R. N. Butler, Chem. Rev. 1984, 84, 249.

2. K. Henrick, R. W. Matthews and P. A. Tasker, Inorg. Chem. 1977, 16, 3293.

3. F. Brady, K. Henrick and R. W. Matthews, J. Organomet. Chem. 1981, 210, 281.
4. J. F. Hinton, K. R. Metz and R. W. Briggs, Prog. NMR Spectrosc. 1988, $20,423$.

5. R. J. Abraham, G. H. Barnett and K. M. Smith, J. Chem. Soc., Perkin Trans. I, 1973, 2142.

6. R. J. Abraham, G. E. Hawkes, M. F. Hudson and K. M. Smith, J. Chem. Soc., Perkin Trans. II, 1975, 204.

7. R. J. Abraham, G. E. Hawkes and K. M. Smith, Tetrahedron Lett. 1975, 1999.

8. J. L. Hoard, Porphyrins and Metalloporphyrins (Edited by K. M. Smith), Elsevier, Amsterdam (1976).

9. P. Rothemund and A. R. Menotti, J. Am. Chem. Soc. 1948, 70, 1808. 